\title{
The frequency variation of Pc5 ULF waves during a magnetic storm
}

\author{
A. $\mathrm{Du}^{1,2}, \mathrm{~W} \cdot \mathrm{Sun}^{2}, \mathrm{~W} \cdot \mathrm{Xu}^{1}$, and X. Gao ${ }^{3}$ \\ ${ }^{1}$ Institute of Geology and Geophysics, Chinese Academy of Sciences, Beijing 100029, China \\ ${ }^{2}$ Geophysical Institute, University of Alaska Fairbanks, AK 99775, USA \\ ${ }^{3}$ Institute of Tibetan Plateau Research, Chinese Academy of Sciences, Beijing 100085, China
}

(Received September 3, 2004; Revised May 30, 2005; Accepted May 30, 2005)

\begin{abstract}
The relationship between Pc5 ULF waves and the asymmetric ring current during the magnetic storm on July 15, 2000 is studied using ground-based magnetometer data and particle observations by the LANL satellite. A frequency decreases of Pc5 is noted during the main phase, which can be attributed to injections of heavier ions $\left(\mathrm{O}^{+}\right.$and $\left.\mathrm{He}^{+}\right)$into the ring current. In addition, it is observed that during the main phase of the storm, the frequency drop of the Pc5 in the IMAGE chain around the MLT midnight is larger than that in the ALASKA chain at MLT post noon. Meanwhile, the longitudinal variation of $\Delta H$ with the maximum around midnight implies a highly asymmetric distribution of the ring current. These results suggested that the frequency variation of Pc5 pulsation during storms is related to the partial distribution in the ring current.
\end{abstract}

Key words: ULF waves, magnetic storm, ring current.

\section{Introduction}

The distribution and time variation of plasma density in the magnetosphere can be estimated from ground-based observations of ULF waves as standing waves of the Alfven mode (Obayashi and Jacobs, 1958; Waters et al., 1991, 1996). Theoretical work suggested the development of the field line resonance model of ULF waves (Tamao, 1966; Chen and Hasegawa, 1974; Southwood, 1974). In the cold plasma, the fast mode wave across the magnetic filed line and is independent on the magnetic field, while the shear Alfven wave is magnetic field line guided. The field line resonance and cavity resonance could generate Pc5 ULF at auroral latitude (Yumoto, 1984; Voelker, 1962; Glassmeier, 1995). The drift-bounce resonance is an internal source of ULF waves (Yeoman and Wright, 2001). Compressional Pc5 ULF waves, found on the nightside close to the flanks of the magnetosphere, are the dominant pulsations at high latitudes during a magnetic storm. Azimuthally polarized toroidal Pc5 pulsations are thought to be a fundamental mode of the toroidal field line resonance (FLR). The resonant frequency of the field line decreases with the increase of plasma density and the length of the field line. The Pc5 ULF waves observed during a storm on July 15, 2000 were identified as field line resonance (Du et al., 2003).

Compressional Pc5 are correlated with the development of the partial ring currents (Anderson, 1993). The partial ring current associated with the asymmetry of the ring current connected to the auroral electrojet in the ionosphere through field-aligned currents (Akasofu et al., 2003). Injections of heavier ions $\left(\mathrm{O}^{+}\right.$and $\left.\mathrm{He}^{+}\right)$into the ring current during the main phase of a magnetic storm were identified

Copy right(c) The Society of Geomagnetism and Earth, Planetary and Space Sciences (SGEPSS); The Seismological Society of Japan; The Volcanological Society of Japan; The Geodetic Society of Japan; The Japanese Society for Planetary Sciences; TERRAPUB. by satellite observations (Daglis, 1997). The strong dawndusk asymmetry of the ring current is caused mainly by $\mathrm{O}^{+}$ and $\mathrm{He}^{+}$ions, but not by $\mathrm{H}^{+}$ions ( $\mathrm{Fu}$ et al., 2001). The increase of heavy ions will affect the resonant frequency of field line.

In this paper, we investigate the variation of the Pc5 frequency and its relationship with longitudinal asymmetry of the ring current during a storm on July 15, 2000.

\section{Data Analysis and Results}

Seven stations of the IMAGE chain (the top 7 rows in Table 1) and four stations in the Alaska array (the middle 4 rows in the Table 1) are adopted for studying the characteristics of Pc5 ULF waves during a storm. Eight stations in middle and low latitudes (the bottom 8 rows) are used to detect the asymmetry of the ring current. The geographic and geomagnetic coordinates of all stations are listed in Table 1. The values of $\mathrm{L}$ for each station are also shown in Table 1 while MLT $_{\text {IMAGE }} \approx \mathrm{UT}+2 \mathrm{hrs}$ and $\mathrm{MLT}_{\mathrm{ALASKA}} \approx \mathrm{UT}-11 \mathrm{hrs}$

Du et al. (2003) studied the characteristics of filed line resonance for Pc5 on July 15-16, 2000. The main frequency of Pc5 ULF waves increases with the decrease of latitude during the storm on July 15-16, 2000. The amplitude peaks of Pc5 ULF waves during the initial phase, main phase and recovery phase occurred near $64^{\circ} \mathrm{N}, 66^{\circ} \mathrm{N}$ and $71^{\circ} \mathrm{N}$, respectively. Figure 1 shows the latitudinal variation of polarization ellipse of Pc5 waves. A linear polarization occurred at MAG with latitude of $66.07^{\circ}$, and polarization changed from counterclockwise to clockwise. It indicates that Pc5 pulsations are generated by field line resonance.

\subsection{Longitudinal asymmetry of the ring current dur-} ing a storm of July 15, 2000

The top panel of Fig. 2 shows $B z$ component of the Interplanetary Magnetic Field (IMF) from Wind satellite, the two middle panels show the total ion fluxes from the 1-20 
Table 1. The list of geographic and geomagnetic coordinates for the magnetic stations.

\begin{tabular}{cccccc}
\hline Station code & $\begin{array}{c}\text { Geographic } \\
\text { latitude }\left(\left(^{\circ}\right)\right.\end{array}$ & $\begin{array}{c}\text { Geographic } \\
\text { longitude/ }\left(^{\circ}\right)\end{array}$ & $\begin{array}{c}\text { Geomagnetic } \\
\text { latitude/ }\left({ }^{\circ}\right)\end{array}$ & $\begin{array}{c}\text { Geomagnetic } \\
\text { longitude/ }\left({ }^{\circ}\right)\end{array}$ & $\begin{array}{c}\text { L-value } \\
(\mathrm{Re})\end{array}$ \\
\hline MAS & 69.46 & 23.70 & 66.07 & 106.92 & 6.22 \\
KEV & 69.76 & 27.01 & 66.21 & 109.73 & 5.36 \\
LOZ & 67.97 & 35.08 & 64.23 & 114.49 & 5.36 \\
SOD & 67.37 & 26.63 & 63.82 & 107.71 & 5.25 \\
PEL & 66.90 & 24.08 & 63.46 & 105.38 & 5.12 \\
HAN & 62.30 & 26.65 & 58.62 & 104.99 & 3.77 \\
DOB & 62.07 & 9.11 & 59.29 & 90.20 & 3.90 \\
\hline BETTLES & 66.90 & 208.45 & 66.46 & 255.27 & 6.35 \\
CIGO & 65.87 & 212.14 & 66.20 & 259.70 & 6.16 \\
EAGLE & 64.78 & 218.84 & 66.44 & 267.16 & 6.26 \\
POKER & 65.12 & 212.57 & 65.60 & 260.90 & 5.85 \\
\hline TAM & 22.79 & 5.53 & 3.33 & 78.35 & 1.07 \\
ABG & 28.60 & 72.90 & 22.84 & 145.40 & 1.20 \\
PHU & 21.00 & 105.95 & 13.99 & 13.99 & 1.08 \\
KAK & 25.23 & 140.18 & 17.95 & 211.39 & 1.12 \\
HON & 21.32 & 202.00 & 21.30 & 269.86 & 1.17 \\
DLR & 29.50 & 259.08 & 38.89 & 326.35 & 1.68 \\
SJG & 18.40 & 293.90 & 29.1 & 5.2 & 1.08 \\
MBO & 14.40 & 343.03 & 23.49 & 58.86 & 1.05 \\
\hline
\end{tabular}

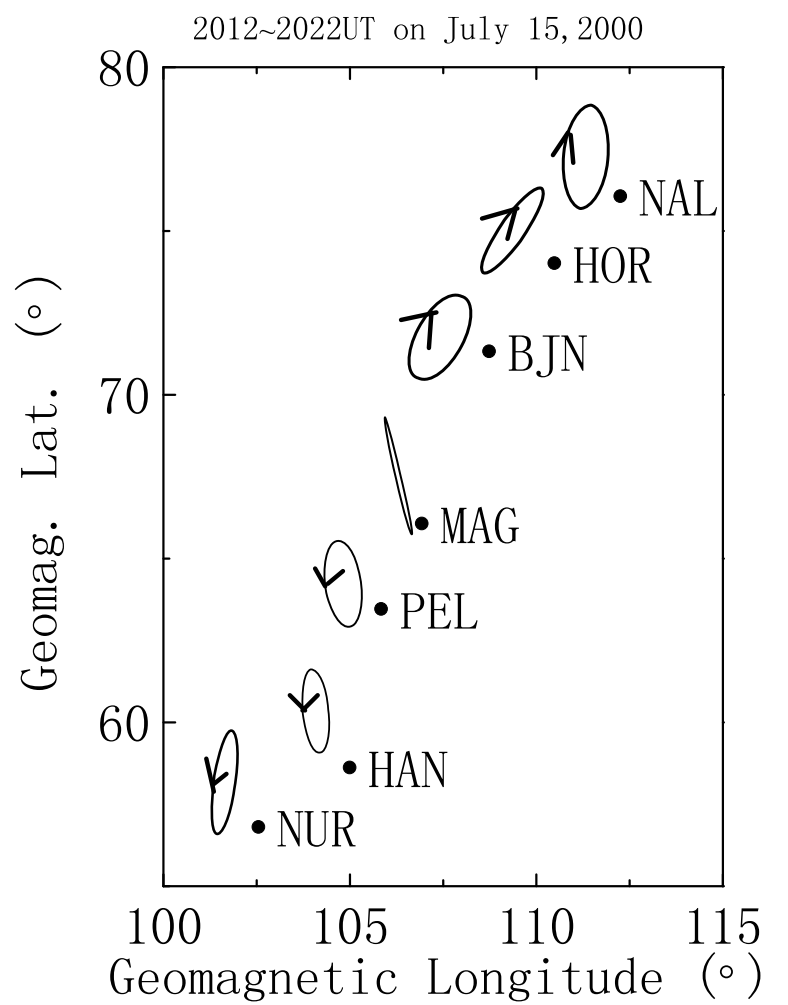

Fig. 1. Snapshot of Pc5 polarization ellipse in IMAGE chain.
keV energy channel of MPA instrument on the LANL satellite and the total density of ions number observed by CPI on the Geotail satellite. The LANL satellite just locates near the IMAGE region at 2100 UT on July 15. There are several peaks of ion fluxes in LANL data and the density of ions observed by Geotail increases sharply. The IMF $B z$ remains southward and the ion flux increases, with several peaks occurring during the main phase. The bottom panel shows contour of the $\Delta H$ at middle and low latitudes together with the Dst index. As seen in the Dst profile, a sudden commencement (SSC) occurred at $1440 \mathrm{UT}$, and then Dst decreased sharply at 1900 UT, arriving at the minimum at 2400 UT on July 15, then increasing slowly in the recovery phase.

The contour of the $\Delta H$ in longitude-UT coordinates is constructed from the observed $H$ component of magnetic disturbances at 8 low-latitude stations. The yellow line in the bottom panel of Fig. 2 shows the magnetic local midnight at different longitudes. The most intense disturbance appeared in the main phase from 1900 UT to 2400 UT of July 15 , and near the $110^{\circ}$ geomagnetic longitude region where the IMAGE chain lies around local midnight, (indicated by the lower horizontal line). The weakest disturbances in $\Delta H$ during the main phase were observed by stations in the ALASKA chain at a longitude of $\sim 260^{\circ}$ which was located just after noon MLT (see the upper horizontal line). Therefore, a clear longitudinal asymmetry in ring current can be identified during the main phase. 


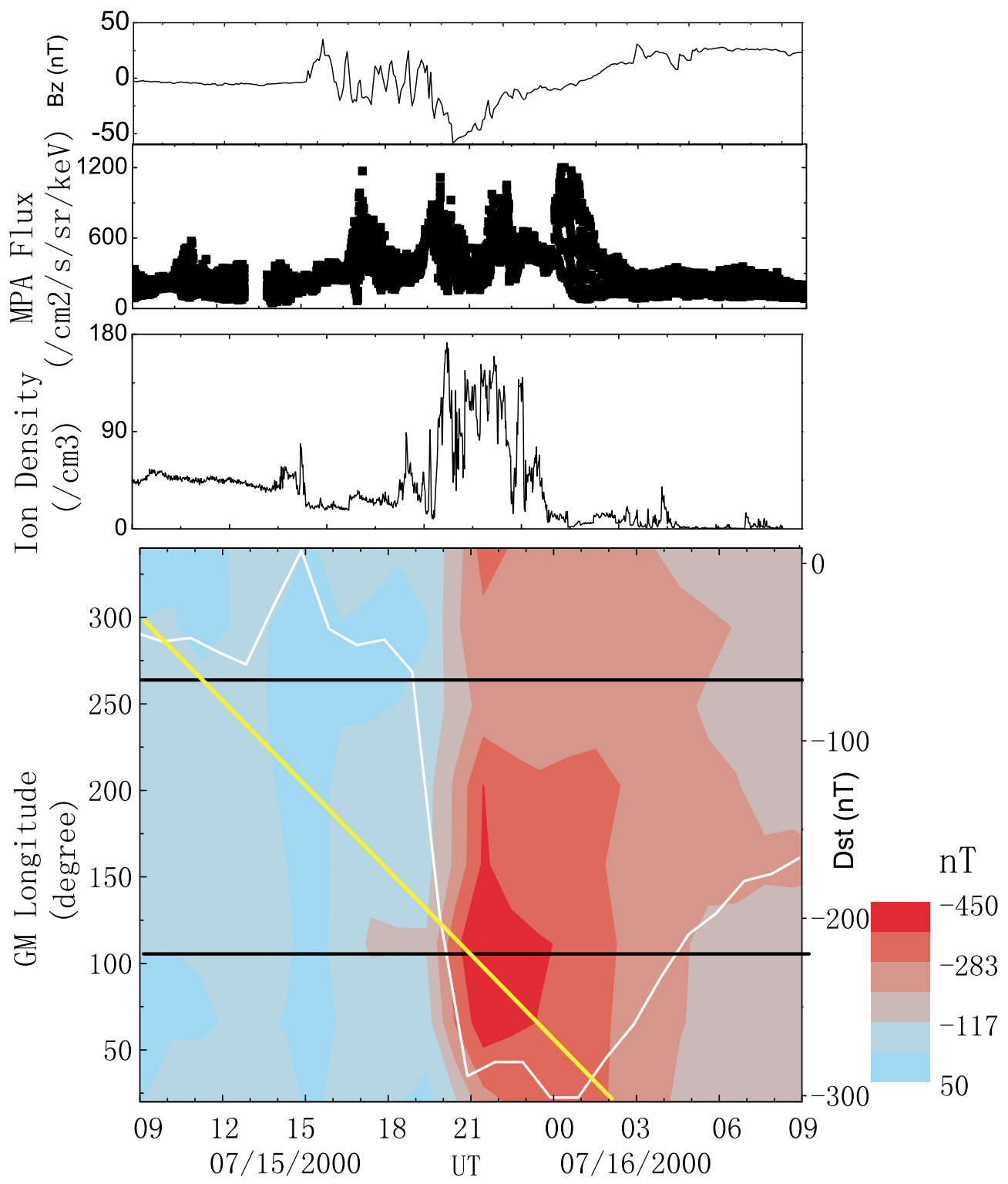

Fig. 2. The IMF $B z$ component from the Wind satellite, ion fluxes from the LANL satellite; the longitudinal-UT distribution of magnetic disturbance, the Dst indices (white line in the lower panel).

\subsection{Wavelet analysis of Pc5 frequency}

To study the Pc5 ULF waves, the data were preliminarily filtered in the $1-8 \mathrm{mHz}$ band by a digital band-pass filter. The Pc5 waveforms at the SOD station in the IMAGE chain and the Poker Flat station in the ALASKA chain are shown in the upper panel of Fig. 3 on July 15-16, 2000.

A Morlet wavelet analysis (Torrence and Compo, 1998), which consists of a plane wave modulated by a Gaussian function $\varphi_{0}(\eta)=\pi^{-1 / 4} e^{i \omega \eta} e^{-\eta^{2} / 2}$, was used to process the pulsation data. The lower panel of Fig. 3 shows the wavelet power spectrum of magnetic disturbances which were observed at SOD station in the IMAGE chain and at Poker Flat in the ALASKA chain during July 15-16, 2000.

It is important to note that the frequency of Pc5 pulsations at the IMAGE stations clearly declined gradually after the initiation of a storm at $1500 \mathrm{UT}$. The frequency reached a minimum at the maximum time of the main phase at 00 UT on July 16. Then it began to increase during the re- covery. Meanwhile, the trend of Pc5 frequency at Alaska stations was similar to that in the IMAGE chain, but the variational amplitudes were much smaller. The Pc5 pulsations frequency dropping during the main phase is obviously associated with the injection of heavier ions $\left(\mathrm{He}^{+}\right.$and $\mathrm{O}^{+}$) into the ring current during the main phase of a storm (Jordanova et al., 2001).

\subsection{Variations of Pc5 frequency and particles in the ring current during a magnetic storm}

In order to show clearly the trend of Pc5 pulsation frequency during a storm, the main frequency in successive half an hour interval for all stations in the IMAGE and ALASKA chains is calculated and shown in the upper and lower panels of Fig. 4. The main frequency of the Pc5 pulsations was defined as the frequency that is associated with the maximum power in the wavelet spectrum. The two solid lines are polynomial fit (the confidence level in the Linear is set to $95 \%$ ) to all points of the main frequency for the 

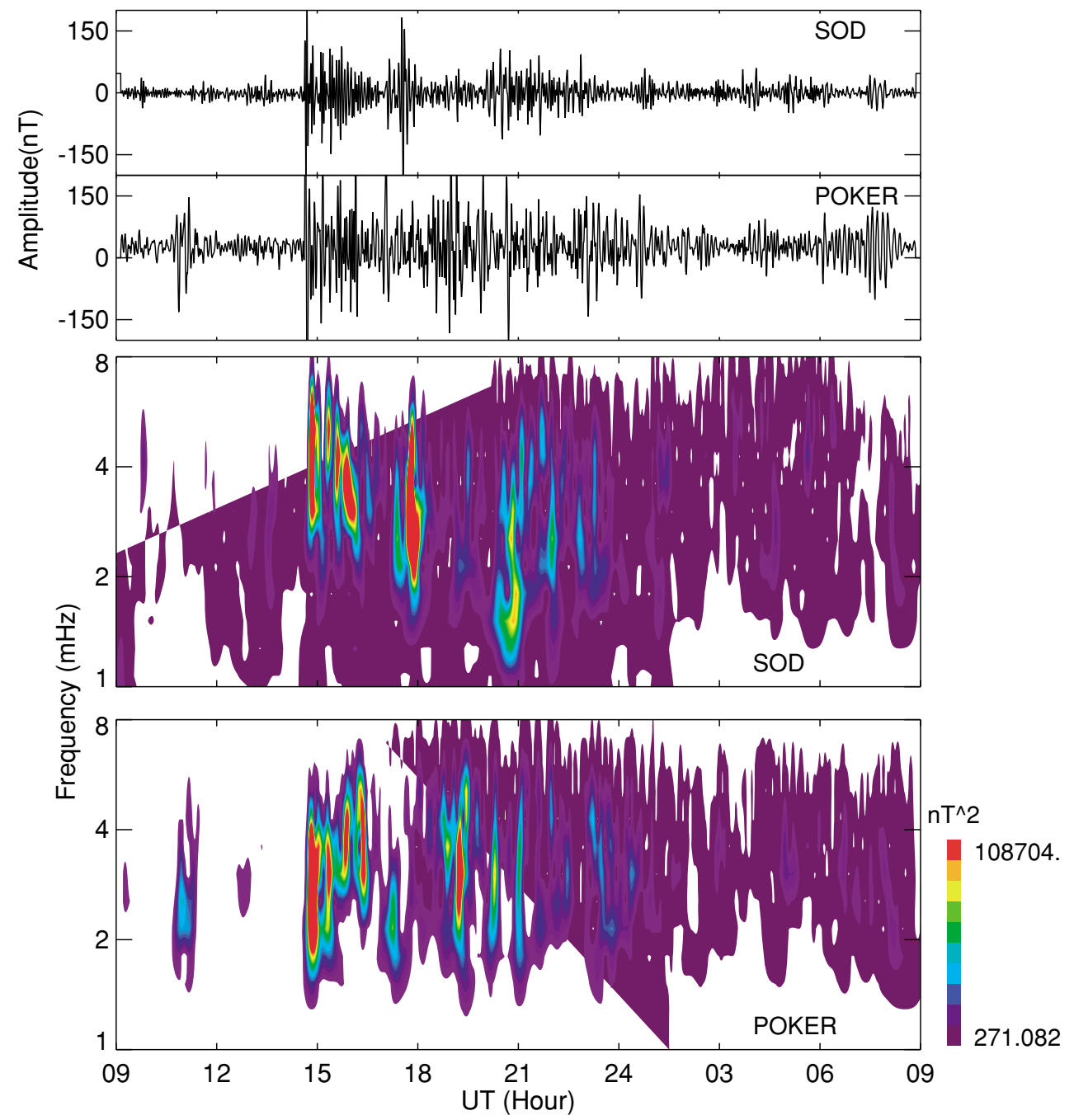

Fig. 3. Filtered pulsations (1-8 mHz) and the normalized wavelet power spectrum of pulsations for the SOD station in the IMAGE chain and Poker Flat station in Alaska chain on July 15-16, 2000.

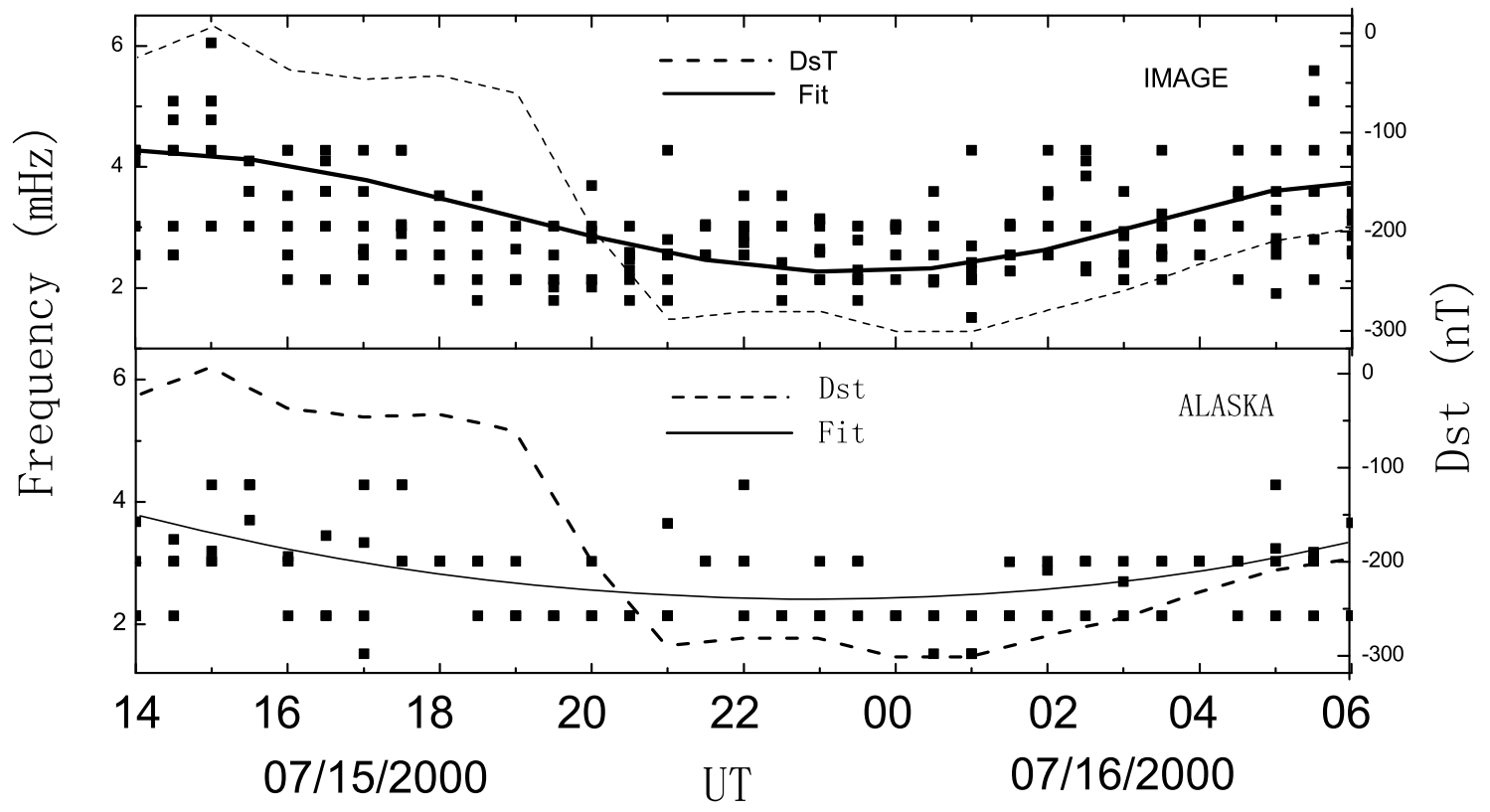

Fig. 4. The variations of the polynomial fit to frequency of Pc5 at seven IMAGE stations and the four ALASKA stations and Dst index during a storm on July 15-16, 2000. 

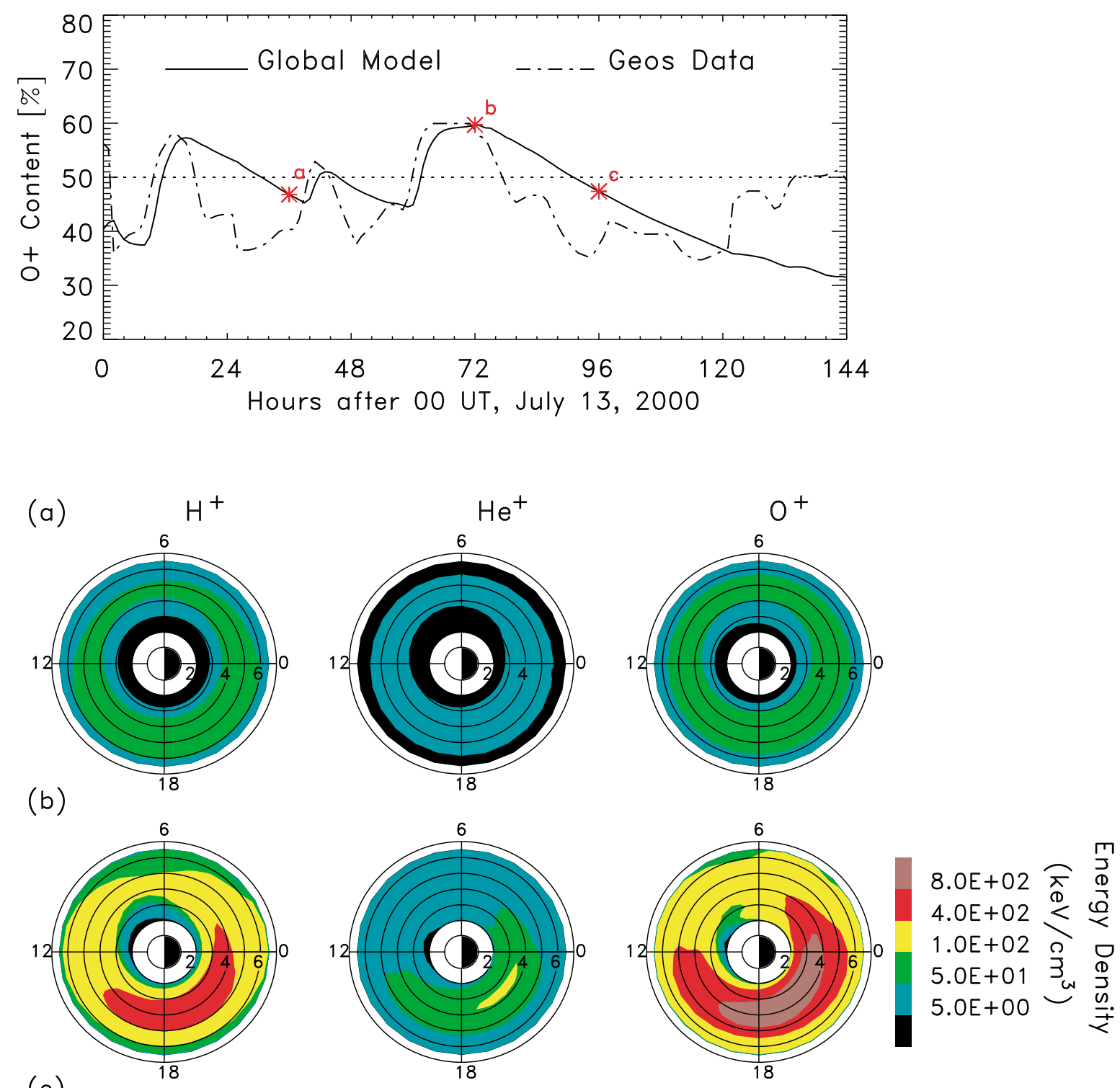

(c)
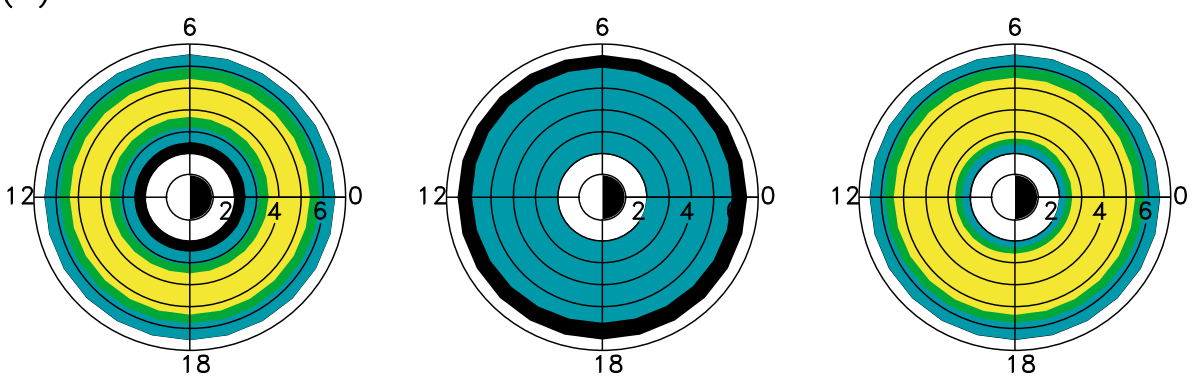

Fig. 5. Top: content of ring current $\mathrm{O}^{+}$. Bottom: $\mathrm{H}^{+}, \mathrm{He}^{+}$, and $\mathrm{O}^{+}$ring current ion energy density at selected hours indicated with (a), (b), and (c) in the top panel (Jordanova and Thorne, 2001).

IMAGE and ALASKA chains, respectively.

It is interesting to note that the main frequency at the IMAGE stations decreased around $3 \mathrm{mHz}$ on average from the initial time to the maximum time of the storm. The minimum of the polynomial fit line locates in the main phase where Dst is less than $-280 \mathrm{nT}$. On the other hand, only about $1 \mathrm{mHz}$ decrease, in the average of the main frequency was found at the Alaska stations. The difference of the main frequency decrease between both chains is believed to arise from the different location of two chains, because the ALASKA stations were located in the post-noon sector and the IMAGE array was in the midnight sector.

The variation of Pc5 frequency may result from the magnetic field topology and plasma mass loading, while the resonant frequency is sensitive to the plasma population where the Alfven speed is at a minimum. The injection of heavier ions, such as $\mathrm{He}^{+}$and $\mathrm{O}^{+}$, into the ring current during the main phase is highly asymmetric. Jordanova et al. (2001) simulated the time evolution of $\mathrm{H}^{+}, \mathrm{O}^{+}$, and $\mathrm{He}^{+}$ in the ring current during a magnetic storm of July 13-18, 
2000. They found that the content of $\mathrm{O}^{+}$in the ring current reached maximum values of $60 \%$ near the minimum value of the Dst index, and an asymmetry in the ring current was evident during the main phase with the maximum energy densities of ions near the dusk sector (see figure 5 in Jordanova, 2001). At the same time, the decrease in amplitude of the magnetic field is only about 1 percent of total magnetic field. The length of field line varies irregularly due to the compression of solar wind pressure and the dipolization of magnetic field. So we conclude that the difference of the main frequency difference between the chains at different MLT is associated with the asymmetry of injected heavier ions $\left(\mathrm{He}^{+}\right.$and $\left.\mathrm{O}^{+}\right)$in the ring current.

\section{Summary and Discussion}

(1) The time variation of Pc5 magnetic pulsation frequency at the IMAGE stations is well correlated to the Dst index during a magnetic storm on July 15-16, 2000. The decrease of Pc5 pulsations frequency during the main phase of a storm indicates enhanced particle injections into the ring current, in particular for heavy ions $\mathrm{O}^{+}$and $\mathrm{He}^{+}$.

(2) The difference of the decrease in frequency of Pc5 ULF waves at between the IMAGE chain and the Alaska chain indicates the asymmetry of injected heavier ions $\left(\mathrm{He}^{+}\right.$ and $\mathrm{O}^{+}$) in the ring current, which is consistent with $\Delta H$ observations at low latitudes.
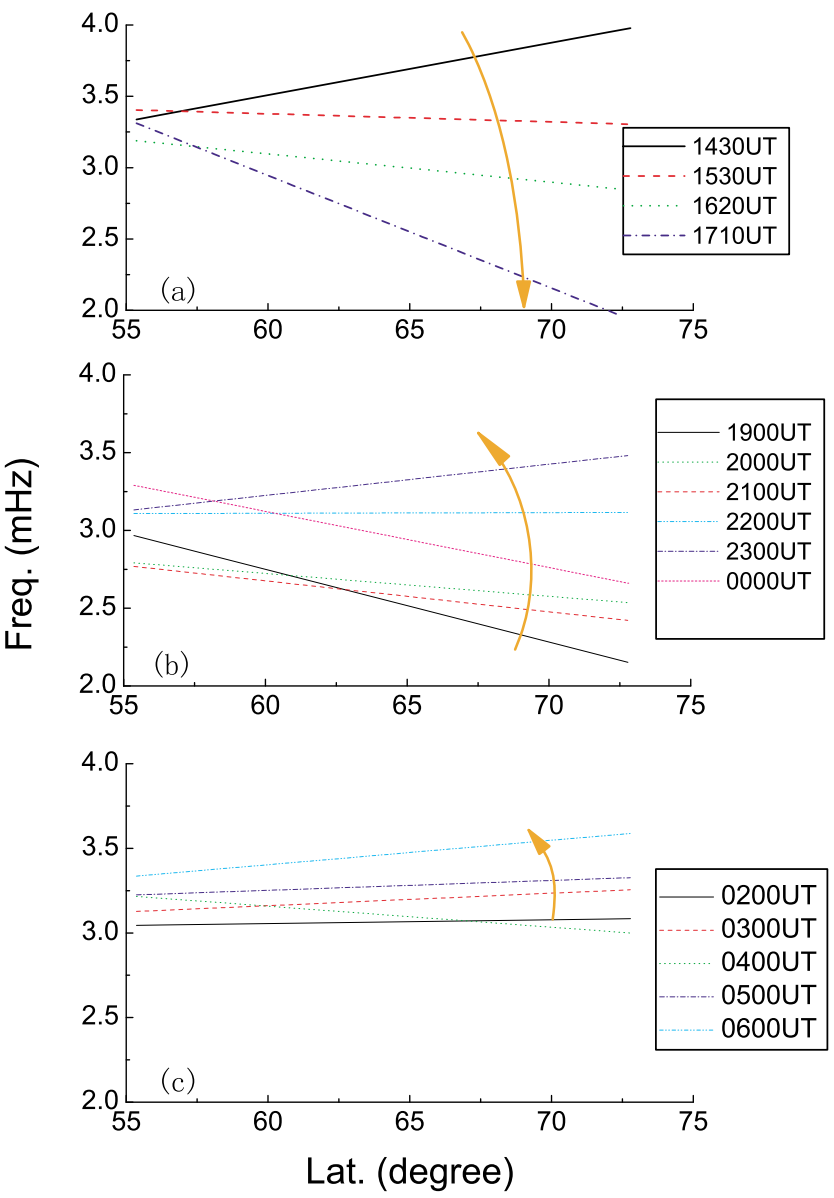

Fig. 6. The variations of Pc5 frequency with the latitude at the internal of 1430-0600 UT in July 15-16, 2000.
Field lines resonance associated with near magnetopause field lines. In the high latitude region, the field lines cross outside the plasmpause, so the wave structure of the observed FLRs will varies with radial distance. The field line eigenfrequency varies depending on a number of factors, including the field line stretching and the plasma density. Waters et al. (2000) showed this behavior of Alfven velocity and resonant period with L shell. In addition, some impulses during a storm usually affect the Pc5 frequency. Waters et al. (1995) and Mathie et al. (1999) also found a diurnal variation in the frequency. It is noted that the lowest Pc5 frequency is always seen at $2 \mathrm{mHz}$ at both stations and the frequency higher than $3 \mathrm{mHz}$ are almost seen at the IMAGE chain in Fig. 4.

Figure 6(a)-(c) show the variations of Pc5 frequency with the latitude for the period 1430-0600 UT, July 15-16, 2000. The different lines in the figure represent the linear fittings of frequency variation for different time intervals. For example, the black solid line indicates the frequency of Pc5 increases with increasing latitude at $1430 \mathrm{UT}$. In the interval 1530 2100 UT, the frequency of Pc5 waves decreases with increasing latitude. In the interval $2100 \sim 0600$ UT, the frequency of Pc5 ULF waves increases with increasing latitude. It suggests that the temporal convection process of ions into the ring current is from higher latitude to lower latitude areas. We can see that Pc5 ULF waves whose frequency is near $2 \mathrm{mHz}$ locates in different latitude. Because the range of latitude in IMAGE chain is wider than that in ALASKA chain, these phenomena result in the Pc 5 frequency distributes broader at the IMAGE chain than at the ALASKA chain.

Acknowledgments. We thank the Finnish Meteorological Institute, and the geophysical institute of the university of Alaska Fairbanks. We would like to thank the many individuals who have provided valuable data including the LANL, WIND, Geotail and the University of Kyoto. This work is supported by NSFC (No. 40304013 and 40236058).

\section{References}

Akasofu, S.-I., W. Sun, and B.-H. Ann, Comments on some long-standing problems in storm/substorm studies, Disturbances in Geospace: The storm-substorm relationship, Geophysical Monograph, 142, 243-254, 2003

Anderson, B. J., Statistical studies of Pc 3-5 pulsations and their relevance for possible source mechanisms of ULF waves, Ann. Geophysicae, 11, 128-143, 1993.

Chen, L. and A. Hasegawa, A theory of long-period magnetic pulsations, J. Geophys. Res., 79, 1024, 1974.

Daglis, I. A., The role of magnetosphere-ionosphere coupling in magnetic storm dynamics, in Magnetic Storms, AGU Monogragh, 98, 107-116, 1997.

Du, A., et al., Characteristics of Pc5 ULF waves during the magnetic storm on July 15-16, 2000, Chinese Geophysics Journal, 46(3), 322327, 2003.

$\mathrm{Fu}, \mathrm{S}$. Y., et al., Temporal and spatial variation of the ion composition in the ring current, Space Science Reviews, 95, 539-554, 2001.

Glassmeier, K.-H., ULF pulsations, in Handbook of Atmospheric Electrodynamics, volume II, Chapter 14, pp. 482-503, 1995.

Jordanova, V. K. and R. M. Thorne, Ring current dynamics during the 13 18 July 2000 storm period, Solar Physics, 204, 361-375, 2001.

Mathie, R. A., F. W. Menk, I. R. Mann, and D. Orr, Discrete field line resonances and the Alfven continuum in the outer magnetosphere, Geophys. Res. Lett., 26, 659-662, 1999.

Obayashi, T. and J. A. Jacobs, Geomagnetic pulsations and the Earth's outer atmosphere, Geophys. J. R. Astr. Soc., 1, 53, 1958. 
Southwood, D. J., Some features of field line resonances in the magnetosphere, Planet. Space Sci., 17, 483, 1974.

Takahashi, K., B. J. Anderson, and S. Ohtani, Multisatellite study of nightside transient toroidal waves, J. Geophys. Res., 101, 24815-24825, 1996.

Tamao, T., Transmission and coupling resonance of hydromagnetic disturbances on the non-uniform Earth's magnetosphere, Sci. Rep. Tohoku Univ., Ser. 5, 17, $43,1966$.

Torrence, C. and G. P. Compo, A practical guide to wavelet analysis, Bull. Amer. Meteor. Soc., 79, 61-78, 1998.

Voelker, H., Zur Breitenabhangigkeit der perioden erdmagnetischer pulsations, Naturwissenschaften, 49, 8-9, 1962.

Waters, C. L., F. W. Menk, and B. J. Fraser, The resonance structure of low latitude Pc3 geomagnetic pulsations, Geophys. Res. Lett., 18, 2293, 1991.

Waters, C. L., J. C. Samson, and E. F. Donovan, The temporal variation of the frequency of high latitude field line resonances, J. Geophys. Res., 100, 7987-7996, 1995.

Waters, C. L., J. C. Samson, and E. F. Donovan, Variation of plasmatrough density derived from magnetospheric field line resonances, J. Geophys. Res., 101, 24737, 1996.

Waters, C. L., B. G. Harrold, et al., Field line resonances and waveguide modes at low latitudes, J. Geophys. Res., 105(A4), 7763-7774, 2000.

Yeoman, T. K. and D. M. Wright, ULF waves with drift resonance and drift-bounce resonance energy sources as observed in artificiallyinduced HF radar backscatter, Annales Geophysicae, 19, 159-170, 2001.

Yumoto, K., Long-period magnetic pulsations generated in the magnetosperic boundary layers, Planet. Space Sci., 32, 1205-1218, 1984.

A. Du (e-mail: amdu@mail.iggcas.ac.cn), W. Sun, W. Xu, and X. Gao 